\title{
José Craveirinha e a declaração da identidade ${ }^{1}$ moçambicana
}

\author{
Vanessa Pincerato Fernandes \\ Marinei Almeida \\ Universidade do Estado de Mato Grosso
}

\begin{abstract}
Resumo
Na poética de Craveirinha, há uma tensão enunciativa que traz vozes silenciadas de um país colonizado, sofrido, sobretudo injustiçado. A partir disso, buscamos refletir a representação do espaço na obra referida, de forma que a cidade e o subúrbio estão diretamente ligados, pois o subúrbio é um espaço que se constitui dentro da cidade, a qual é considerada por Macedo (2008) como espaço literário, como lugar de encontros e desencontros do contraditório. Assim, em Karingana ua Karingana, temos esses espaços contradizendo-se e apresentando contrastes evidentes e marcantes. Nesse sentido, nossa proposição centra-se na análise de poemas da obra escolhida, do poeta moçambicano José Craveirinha, por meio de reflexões que discutirão a representação desses espaços (cidade/subúrbio), uma vez que o bairro de cimento é visto como lugar de exploração, de sofrimento, de denúncia em meio à crítica ao regime colonial por um processo de produção das diferenças em um mundo onde o espaço social, cultural e econômico estão interligados.
\end{abstract}

Palavras-chave: espaço; subúrbio; cidade.

\begin{abstract}
In Craveirinha's poetics, there is an enunciative tension that brings silenced voices from a colonized country, suffered, mainly wronged. From this, we seek to reflect the representation of space in the work, so that the city and the suburb are directly linked, because the suburb is a space that can be seen within the city, qualified by Macedo (2008) as literary space, as place of encounters and mismatches of the contradictory. Thus, in Karingana ua Karingana, these spaces are contradictory and present striking and striking contrasts. In this sense, our central proposal for the analysis of poems of the chosen work, by the Mozambican poet José Craveirinha, through reflections that discuss the representation of these spaces (city/suburb), once in the cement neighborhood is seen as a place of exploration, suffering, denunciation amid criticism of the colonial regime for a process of production of differences in the world where the social, cultural and economic space are interconnected.
\end{abstract}

Keywords: space; suburb; city.

Recebido em: 27/05/19

Aprovado em: 02/08/19

\footnotetext{
${ }^{1}$ Termo utilizado por Mbembe (2017), segundo o qual é difícil a constituição da identidade negra por esta ser permeada por interesses escusos.
} 
Craveirinha destaca um importante papel temático de origem familiar, geográfica, cultural e linguística. Ressalta ainda o espaço de valorização do negro (poeta, espaço e poesia). Seus poemas levantam críticas e propõem combate à situação imposta pelo colonialismo centrado. Esta empreitada provocou verdadeira modificação no campo cultural daquele país e serviu como caminho inspirador para vários poetas. Consequentemente, a poética de Craveirinha, pautada na transição por entre os espaços da cidade de cimento e do Mafalala, brancos e negros, e em meio ao constante trabalho com a linguagem, toma forma, a ponto de extravasar o limite local, em que a vida se materializa em matéria poética. Assim está concomitantemente presente nos versos de Craveirinha, em meio ao período de colonização de Moçambique, o espaço da cidade colonizada, enquanto local fixo, pois

Nascido no Xipamanine, outro bairro popular, José Craveirinha foi, durante uma fase, morador da Av. Vinte e Quatro de Julho, importante artéria da zona central da cidade. Indagado sobre esse tempo vivido na cidade de cimento, em tom de blague, explica: "Era um inocente, não tinha poder de escolha". (CHAVES, 2005, p. 142)

Com isso, a saída de Craveirinha do bairro de Caniço, ainda enquanto criança, para viver com o pai na cidade de cimento, gerou mudanças e acréscimos em sua poética. Segundo Chaves (2005) "com a mudança, abre-se um outro universo, povoado de referências interditadas aos moradores dos subúrbios: outra língua, outros hábitos, outros valores, outra forma de estar no mundo" (p. 142). Essa transição se torna pano de fundo não somente para denunciar as injustiças que a colonização impôs, mas principalmente como lugar de uma busca identitária, como veremos nos poemas "Ao meu pai ex-emigrante" e "Mãe".

A transição do poeta do chamado bairro de caniço para o bairro de cimento tem uma enorme contribuição no seu fazer poético. A pluralidade de situações vivenciadas nessa transição é o que caracteriza a obra aqui estudada. $\mathrm{O}$ deslocamento de espaços na poética de Craveirinha comparece como uma imagem de uma possível "mundividência", para a construção de uma imagem de si mesmo. Temos com isso o subúrbio como espaço existencial do negro, em que o poeta se sedimenta em contraste com a cidade, que é o espaço hegemonicamente do branco. O poeta enuncia em suas poesias relatos do dia a dia. Ele opta por escrever sobre a história de seu tempo em sua terra, em um espaço de tempo que transita entre a colonização e a independência. $\mathrm{O}$ poeta reflete em seus poemas sempre o real vivido; de acordo com Leite (2002), “o tema cidade/subúrbio revela-se, pois, como lugar literário vital de tensão, ao denunciar as injustiças que a civilização do europeu leva a construir, e ao problematizar a vida do colonizado" (p. 115). 
Os espaços entre cidade e subúrbio são considerados espaços eminentemente socioculturais, pois

Consideramos espaço sociocultural a representação do conjunto de crenças, símbolos, mitos, actividades ritualísticas, concepções do mundo e modos de vida traduzidos em modelos comportamentais determinados, aprendidos, partilhados e integrados (ou não) numa tradição, e que são realizados por um colectivo de personagens devidamente localizado. (NOA, 2002, p. 172)

Assim, ao falarmos dessa trajetória de Craveirinha e da vivência nestes dois mundos, cidade e subúrbio, nos sentimos instigadas a empreender uma reflexão sobre a "declaração da identidade" no espaço poético do poema "Carta ao meu belo pai ex-emigrante"; assim, por meio de Mbembe, podemos dizer que "[...] o Negro se diz de si mesmo que é aquilo que não foi apreendido; aquele que não está onde se diz estar, e muito menos onde o procuramos, mas antes no lugar onde não é pensado" (MBEMBE, 2017, p. 59).

Por outras palavras, em matéria de identidade, tradição ou autenticidade, é impossível, ou pelo menos difícil, distinguir o original da sua cópia, pois, de acordo com Mbembe, o negro era tido como simulacro, ou seja, não era tal como é, era construído pelo olhar do outro. Este termo, citado por Mbembe, trata da questão da identidade negra que só poder ser problematizada enquanto identidade em devir. Nesta perspectiva, o mundo deixa de ser, em si, uma ameaça. Pelo contrário, o mundo torna-se uma vasta rede de afinidades, em que "[...] há uma identidade em devir que se alimenta simultaneamente de diferenças entre Negros, tanto do ponto de vista étnico, geográfico, como linguístico, e de tradições herdeiras do encontro com Todo o Mundo" (MBEMBE, 2017, 166-167).

Dessa forma, veremos, apoiados em Hall (2009) e Mbembe (2017), as posições que o sujeito negro assume na obra Karingana ua Karingana (1995), sujeito esse enunciado na voz poética e no espaço dos poemas, não se restringindo às fronteiras de seu território espacial, em que "as identidade nacionais não são coisas com as quais nós nascemos, mas são formadas e transformadas no interior da representação" (HALL, p. 48, 2006).

As identidades não podem de forma alguma ser idênticas, pois são estas que assumem formas diferentes e sofrem mudanças pelo processo de colonização. Com isso, Mbembe certifica que é difícil à constituição do termo identidade negra, pois ela é repleta de meandros e interesses escusos. Por meio dessa reflexão dialogaremos com o autor a propósito das formulações sobre uma crítica política da raça, do racismo e do colonialismo, em torno da declaração de identidade na obra de Craveirinha.

Sem negar as ambiguidades características das construções de identidades, vemos, na poética de Craveirinha, o poeta assumir o contraditório para valorizar, em meio a um 
processo de construção da identidade pós-colonial, ${ }^{2}$ as referências culturais desprivilegiadas pela assimilação cultural.

Nesse contexto, o termo pós-colonial surgiu na década de 1980. Alguns o entendem como a situação em que vivem ou viveram as sociedades que apareceram depois da inserção do sistema colonial, ou seja, refere-se a sociedades que começaram a regular a sua existência com o advento da independência. Porém, segundo Mata,

o pós-colonial não tem necessariamente a ver com a linearidade do tempo cronológico, embora dele decorra [pois a questão não é simplesmente de posterioridade temporal; tem a ver com uma sequência lógica e histórica], denuncia a sua marca da dependência e um compromisso contraditório com o empreendimento que o precedeu [o colonial] e possibilitou e que, para combater, tem de digerir. (1993, p. 36-37)

Assim, a condição que Craveirinha se manifesta enquanto consciência do pós-colonial, pois independe do tempo cronológico, uma vez que o tempo histórico ou o conjunto de atribuições teóricas dão possibilidade de interpretação considerando a sua relação com o contexto.

Nesse ponto, o uso do termo identidade é tanto simbólico quanto social. Este surge como outra perspectiva dos estudos pós-coloniais, que são os estudos subalternos. Neste, os valores simbólicos da luta para afirmar as diferentes identidades apresentam causas e consequências materiais. Deste modo, a escrita de Craveirinha é porto poético da afirmação de uma declaração de identidade em que o sujeito que está à margem representa e apresenta seus valores culturais. Neste sentido, Spivak afirma: "Nos estudos subalternos, devido à violência da inscrição epistêmica imperialista, social e disciplinar, um projeto compreendido em termos essencialistas deve trafegar em uma prática textual radical de diferenças" (2010, p. 76).

Nesse limiar, o poema "Ao meu belo pai ex-emigrante", parte da saudade do pai, em que a arquitetura das palavras delineiam e, com grande poder declamatório, desenvolvem linhas fundamentais que percorrem, em meio à saudade do pai, os marcos de uma consciência identitária moçambicana. Este poema instiga-nos a interrogar o que é ser moçambicano, e ao mesmo tempo observar as características da declaração de uma identidade moçambicana que estão intrinsicamente ligadas ao fenômeno do nacionalismo. Assim, concordamos com a opinião de Mbembe quando

\footnotetext{
${ }^{2}$ A condição que o poeta assume é a da consciência do pós-colonial, pois independe do tempo cronológico, uma vez que o tempo histórico ou o conjunto de atribuições teóricas dão possibilidade de interpretação considerando a sua relação com o contexto (MATA, 1993). Dessa forma, alguns estudos sobre o pós-colonialismo, que não devemos confundir com pós-independência, devido ao fato de não estar relacionado ao tempo cronológico, referem-se à situação em que vive(ra)m as sociedades que emergiram depois da implantação do sistema colonial, enquanto, para outros, o "pós" do significante "colonial" refere-se às sociedades que começam a agenciar a sua existência com o advento da independência e sobretudo de tradição anglo-saxônica. Assim, nesta classificação (pós-colonial) não se trata de cronologia e sim de temáticas que apontam para o futuro.
} 
observa que esse tipo de reflexão “[...] apresenta características próprias. Libertário, biográfico, histórico, político, é produto de uma internacionalização poliglota” (2017, p. 62).

No poema, desenvolvem-se linhas fundamentais que percorrem de forma substancial uma poesia elegíaca. Aqui, em meio à saudade do pai, enfatizam-se os marcos de uma consciência que se confirma africana. As estrofes, de grande dimensão, é característica da presença forte da dramatização, pois "as maternas palavras de signos/ vivem e revivem no meu sangue", ${ }^{3}$ falando ao pai de onde ele vem, do sangue da Mãe e do lugar de onde ele fala; contudo, ao ser tocado pela memória saudosa, os termos usados, como "ronga-ibérico", "afro-puro", "afro-algarvia" mostram que Craveirinha não se esquece de sua mestiçagem, como vemos neste verso: "para ti, meu Pai, minha homenagem de caniços", que mostra o lugar e a origem que o poeta escolheu.

Em um tecer literário que africaniza a figura paterna, temos a presença de um espaço de integração com a terra escolhida, África, transitando do "antigo português puro", daquele que deixa laivos "do luso-arábico Aljezur da tua infância", para afirmar-se como aquele cujo "sangue se moçambicanizou nos torrões/ da sepultura de velho emigrante...", como o "meu resgatado primeiro ex-português/ número UM Craveirinha moçambicano!". Pela consciência africana, o olhar do filho é capaz de expressar a saudade do pai, construída em um espaço intervalar, entre a língua do colonizador e a do colonizado, em que se busca no trânsito entre os espaços (caniço e cimento), um espaço de integração com a terra escolhida pelo poeta, em que a imagem do pai se constrói e se torna possível à afirmação na multiplicidade própria a singularidade da pátria à qual Craveirinha escolheu pertencer.

A memória frutifica no intervalo entre os tempos, fazendo confluir passado e presente, em que a carga emocional, os sentimentos conflituosos, entre saudade do pai, mas não de sua origem algarvia, desencadeada pela lembrança das palavras, das ações e o percurso partilhado com o pai, demarcam o espaço do existir.

Podemos pensar, nesse sentido, uma das marcas da condição pós-colonial, nessa abertura de novos espaços e a recusa das instituições e significações do colonialismo, estas que são características dos regimes do pós-independência.

Nesse contexto, Craveirinha constrói um texto poético em que os resquícios da memória são conscientemente engendrados pelo olhar em que "o Zé de cabelos crespos e aloirados" é capaz de recolher as reminiscências filiais para compor um novo conhecimento acerca daquele que o gerou.

A memória saudosa do pai, que permeia os versos "Pai:/ Ainda me lembro do teu olhar/ e mais humano o tenho agora na lucidez da saudade", e ainda: "E choro-te/ chorando-me mais agora que te conheço", opera como um processo de reconhecimento e de reconstrução

3 Todas as referências a versos de "Ao meu belo pai ex-emigrante" pertencem à edição CRAVEIRINHA, (1995, p. 92-95). Faremos referências aos versos do poema, que, por ser extenso, apresenta-se em anexo na íntegra. 
pela expressão lírica, a imagem do pai e do próprio poeta, pelo olhar do colonizado, pautado pelo viés da saudade. $\mathrm{O}$ ato de lembrar perfaz uma inerente descontinuidade contra a qual se insurge o ser, assim: "Na maior parte das vezes, lembrar não é reviver, mas refazer, reconstruir, repensar, com imagens e ideias de hoje, as experiências do passado. A memória não é sonho, é trabalho" (BOSI, 1994, p.55).

O eu poético se volta à memória do pai, do modo de compreender-se a partir dele, chamado aqui por linha de "fronteira"; superados os rígidos limites que demarcavam os dois universos culturais. Nestes em que o poeta nasceu e viveu, temos na hierarquia social, já não ditada pelas referências plantadas pelo colonialismo, um pedaço que ainda guarda singularidades, que as muitas transformações sofridas pela cidade não aboliram.

Neste poema temos a imagem do pai aproximando Craveirinha aos seus traços físicos; contudo, há um distanciando em relação à identidade de ambos. Torna-se possível, no entanto, vermos a construção de uma imagem de si:

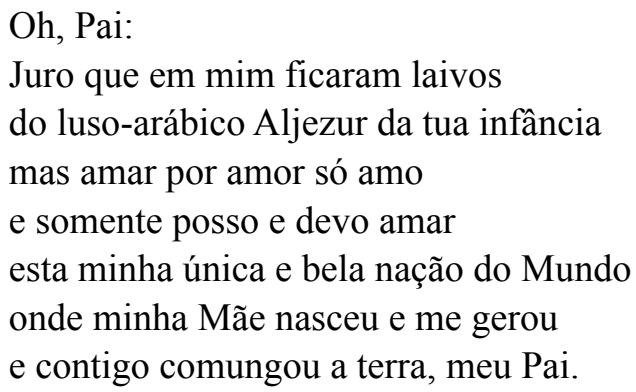

Resgatar (1) o pai e falar (2) da vivência nestes dois mundos, cidade e subúrbio, reafirma a busca de uma "declaração da identidade", termo utilizado por Mbembe (2017), tornando a origem híbrida. O sangue europeu mescla-se ao africano neste poema, não como fonte de conflito, hesitação ou culpa, mas sim torna-se o porto de partida de uma viagem realizada para a afirmação de um universo cultural, onde sua obra é tradução e energia, pois "se africanizaram para a eternidade nas minhas veias/ e o teu sangue se moçambicanizou nos torrões".

Essas questões também estão presentes no poema "Mãe", em que o eu poético afirma o lugar de onde veio ao se referir ao sangue e ao ventre materno. Este poema remete à saudosa lembrança da mãe, após sua morte, como uma elegia a tudo que foi vivido e se reafirmando no espaço, no lugar, de onde viveu com a mãe "no meio das baladas à volta da fogueira". Lugar este em que a vivência de Craveirinha, entre estes dois mundos e duas línguas, que incansavelmente citamos, está em consonância com Fanon, segundo o qual "a zona habitada pelos colonizados não é complementar da zona habitada pelos colonos" (FANON, 1968, p. 28). Nesta oposição:

A insistência do menino em continuar a falar a língua dos primeiros anos indicia já um sinal da escolha que o homem faria, e a poesia viria confirmar. Evocadas em tantos 
poemas, as imagens da mãe e da avó remetem às referências matriarcais em que o poeta enraíza a sua identidade. Sempre que a escolha for imperiosa, a dimensão africana que compõe a sua mestiçagem é que definirá o seu lugar. Quando o conflito se expõe, será firme a postura de quem não pode e não quer prescindir de um legado essencial para a poesia e para a vida. (CHAVES, 2005, p. 143)

Vivenciada, desde tão cedo, a divisão entre esses dois mundos poderia, é certo, ter gerado a incompreensão e o ressentimento. Nas palavras de Chaves (2005, p. 145), "os deslocamentos, possibilitando a pluralidade, provocaram, todavia, outra reação. Deslocar-se de um polo a outro num cenário onde a segregação era a norma teve fortes consequências", pois o poeta, na recusa do que poderia vir de positivo de um dos lados, toma como princípio a rejeição da exclusão. Sua escrita poética atesta em muitos momentos a capacidade de articular contrários, sem esvaziar a riqueza da contradição, tornando-se assim um espaço de elementos que podem coexistir. Contudo, não podemos deixar de observar que Craveirinha reconhece essa mestiçagem, e isso é muito importante em sua poesia.

Os lugares físicos de Moçambique aparecem bem demarcados no poema "Ao meu belo pai ex-emigrante", em que Craveirinha se despede do pai, com as palavras: "Pois o material da poesia são as palavras [...]. As palavras são usadas para os corriqueiros propósitos diários e são o material do poeta, tal como os sons são o material do músico" (BORGES, 2000, p. 83), palavras estas que conferem a imagem de um moçambicano, "semiclaro/seminegro", gerado no ventre de uma "Tombasana", que significa moça jovem, rapariga jovem:

\author{
E na minha rude e grata \\ sinceridade filial não esqueço \\ meu antigo português puro \\ que me gerastes no ventre de uma Tombasana \\ eu mais um novo moçambicano \\ semiclaro para não ser igual a um branco qualquer \\ e seminegro para jamais renegar \\ um glóbulo que seja dos Zambezes do meu sangue
}

Craveirinha, nestes versos, deixa bem claro de onde vem e sua mestiçagem, mas confirma em sua escrita poética que jamais renegará que há em seu sangue águas do “Zambeze”, rio mais extenso e que corta Moçambique de uma ponta a outra.

A representação literária desse espaço de Moçambique, na obra de Craveirinha, no sentido de uma declaração de uma identidade moçambicana e híbrida, aparece nos versos do poema "Ao meu belo pai ex-emigrante" como uma imagem do espaço sendo delineada pela palavra: "a minha mãe agonizando na esteira em Michafutenel os bolsos cheios de tingolé da praia/ da estrada do Zinchacha onde eu nasci” (grifos nossos). 
"Michafutene" é o nome de uma localidade da periferia da capital; "tingolé", fruto silvestre pequeno; "Zinchacha", nome próprio de uma rua da antiga Lourenço Marques. "A imagem nunca é um 'elemento': tem um passado que a constituiu; e um presente que a mantém viva e que permite a sua recorrência" (BOSI, 2000, p. 14-15). Nesse sentido, a representação desses lugares físicos em meio à homenagem ao pai é a reafirmação do poeta enquanto moçambicano, sem renegar sua origem "semiclara" proveniente do pai "ex-português".

O eu lírico, ao dar explicações e exemplificações, remonta bem longe na caminhada histórica do sujeito: interroga o pai e escuta os "xitututo Harley Davidson" e, tal como Fernando Pessoa, que no "Mar português" fez das lágrimas dos portugueses sal do mar, José Craveirinha deu um outro sabor com as águas do Zambeze em seu sangue: "esta minha única e bela nação do Mundo/ onde minha Mãe nasceu e me gerou”. Dessa forma, Craveirinha, partindo da literatura colonial como pano de fundo de um processo histórico (a colonização) e um sistema (o colonialismo), nos mostra que "inevitavelmente, a literatura colonial acaba por ser ou co-actuante ou consequência de um fenómeno que tem subjacentes motivos de ordem psicológica, social, cultural, ideológica, estética, ética, económica, religiosa e política" (NOA, 2002, p. 60), no sentido de que é a partir da "cidade do colonizado" que a poética de Craveirinha busca "[...] salvar da decadência absoluta aquilo que foi condenado à insignificância" (MBEMBE, 2017, p. 68).

Nessa perspectiva, ao falar de Craveirinha, Gameiro ressalta que "o seu eu poético apresenta-se mesclado - miscigenado — de elementos civilizacionais de matriz europeia e de matriz africana" (GAMEIRO, 2005, p. 92). Na poesia de Craveirinha, os lugares de origem, mesclados com a língua europeia do pai, remontam à questão do reconhecimento de sua mestiçagem. Perante isso, o poeta traz a "mistura" desses espaços, dos conflitos e contradições provenientes da origem mestiça que correspondem à soma de sua miscigenação, e ainda, da origem advinda de sua cultura negro-africana. Desse modo, Gameiro analisa a escrita de Craveirinha ressaltada no texto poético, a partir da observação do eu poético, fundido ao próprio espaço vivido, em que "[...] o eu é a pedra angular. O sujeito afirma-se, continuadamente, identificando-se, revendo-se nos valores e cultura que defende e acredita. É notório o tom panegírico com sabor a autorretrato, pois o eu que procura dizer-se está no centro de tudo" (2005, p. 63). Nesse ponto de vista, a palavra é capaz de elaborar essa imagem, e pode ser mais real do que uma própria fotografia, pois aqui o poeta humaniza as coisas.

\begin{abstract}
E nestes versos te escrevo, meu Pai por enquanto escondidos teus póstumos projectos mais belos no silêncio e mais fortes na espera porque nascem e renascem no meu não cicatrizado ronga-ibérico mas afro-puro coração.
\end{abstract}


Edward Said faz considerações a respeito da literatura produzida durante o período colonial, em que “[...] considera que esta literatura efectivamente silencia o Outro, reconstitui a diferença como identidade, regula e representa espaços dominados por forças de ocupação, e não por habitantes inactivos" (SAID, 1990, p. 166). Em diálogo, Noa considera que "[...] fazendo do estereótipo (racial e cultural) o fundamento da sua interpretação não especificamente da literatura colonial, mas do discurso colonial" (NOA, 2002, p. 62), ou seja, Craveirinha enquanto sujeito consciente mostra em seu fazer poético, presente no poema "Ao meu belo pai ex-emigrante", a situação colonial imposta diante da sua origem mestiça.

Conforme Bachelard (1993), lembramos que a função do espaço se pauta no tempo. Nesse sentido a escrita de Craveirinha constitui um elemento de identidade entre os oprimidos em luta contra essa dominação, durante o período colonial.

Por mais que Craveirinha reconheça sua mestiçagem, por meio da transição entres os espaços físicos, o eu poético reafirma a identidade negra, chamada por Chaves de Negritude:

No apego tão firme a esse patrimônio cultural, pode-se ler mais sobre o itinerário poético e existencial de Craveirinha. Lê-se, por exemplo, que sua origem mestiça não esbateu a consciência de que a dignificação do negro era um dos pressupostos para a libertação nacional, o que vem explicar a ligação de seu nome ao movimento da Negritude. Teria sido, aliás, um dos representantes de Moçambique no célebre caderno Poesia negra de expressão portuguesa, editado no começo da década de 50, em Lisboa, pela combativa Casa dos Estudantes do Império. Consta da história oral da edição que sua ausência foi motivada apenas pelo atraso com que sua contribuição chegou a Portugal, problema incontornável naquele tempo de urgências. (CHAVES, 2005, p. 151-152)

Se a especificidade é a afirmação de um desvio em relação a uma norma geral, nesse caso a norma é dada pelo colonialismo, e é em relação a este que se define o perfil de subalterno em relação ao colonialismo português. Tal subalternidade, na poesia de Craveirinha, é ressignificada, pois o que é ser subalterno? É despojar-se? Ou ainda acomodar-se, revestir-se da condição colonial? Para Spivak, não se pode falar pelo subalterno, mas pode-se trabalhar "contra" a subalternidade, criando espaços nos quais o subalterno possa se articular e, como consequência, possa também ser ouvido (SPIVAK, 2010, p. 16).

No entanto, nos versos de Craveirinha temos a dicotomia subúrbio/cidade e a valorização da cultura, do território nacional e da própria língua. Plasmam-se o português e o ronga, por algumas razões, pois como já citamos, o poeta era filho de pai português e mãe moçambicana. Sendo a segunda criada em berço africano (país colonizado), e o primeiro pertencente a Portugal (país colonizador), cria, pois, uma dicotomia que percorre os poemas "Mãe" e "Ao meu belo pai ex-emigrante", nesse sentido:

Não se trata de reler a História, gratuitamente, mas de revisitar um imaginário com toda a sua carga de preconceitos, contradições, manipulações, deformações e 
conspirações, precavendo, talvez o futuro, - e o presente, naturalmente - dos estigmas da incomunicabilidade cultural e civilizacional. (NOA, 2002, p. 67)

Ao reler a história de Craveirinha, dizemos que a separação taxativa entre a Europa (pai) e a África (mãe), no processo de colonização, é uma herança do colonialismo e não foi mais do que um conceito artificial construído pelas ideologias coloniais.

\section{Referências}

BACHELARD, Gaston. A poética do espaço. São Paulo: Martins Fontes, 1993.

BORGES, Jorge Luis. Esse ofício do verso. Org. Caliu-Andrei Mifailesceu. Tradução: José Marcos Macedo. São Paulo: Companhia das Letras: 2000.

. O ser e o tempo da poesia. São Paulo: Companhia das Letras, 2000.

BOSI, Ecléa. Memória e sociedade. 3. ed. São Paulo: Companhia das Letras, 1994.

BRANDÃO, L. A. Espaços literários e suas expansões, Aletria, Belo Horizonte, v. 15, edição única, p. 207-220, jan.-jun. 2007. dez. 2012.

. Tensões do espaço literário. Aletria, Belo Horizonte, v. 22, n. 3, p.193-203, set.-

CHAVES, Rita. Dados biográficos e matéria poética na escrita de José Craveirinha. In:

Angola e Moçambique: experiência colonial e territórios literários. Cotia, SP: Ateliê, 2005.

CRAVEIRINHA, José. Karingana ua Karingana. 3. ed. Maputo: Associação dos Escritores Moçambicanos/Instituto Nacional do livro e do Disco/Instituto Camões, 1995.

FANON, Frantz. Os condenados da terra. Tradução: José Laurêncio de Melo. Rio de Janeiro: Civilização Brasileira, 1968.

GAMEIRO, Armindo da Costa. O espaço autobiográfico em José Craveirinha. Lisboa: Imprensa Nacional-Casa da Moeda, 2005.

HALL, Stuart. Da diáspora: identidades e mediações culturais. Belo horizonte: UFMG, 2003.

. A identidade cultural da pós-modernidade. Tradução: Tomaz Tadeu da Silva, Guaracira Lopes Louro. 11. ed. Rio de Janeiro: DP\&A, 2006.

. Quem precisa da identidade? In: SILVA, Tomaz Tadeu da (org.). Identidade e diferença: a perspectiva dos Estudos Culturais. Petrópolis: Vozes, 2009. p. 7-72.

LEITE, Ana Mafalda. A fraternidade das palavras, Via Atlântica, São Paulo, v. 1, n. 5, p. 20-28, out. 2002.

MACEDO, Tania Celestino de. A presença da literatura brasileira na formação dos sistemas literários dos países africanos de língua portuguesa, Via Atlântica, São Paulo, v. 1, n. 13, p. 123-152, jun. 2008.

MATA, Inocência. História e ficção na literatura angolana: o caso de Pepetela. Lisboa: Colibri, 1993. 
MBEMBE, Achille. Crítica da razão negra. 2 ed. Tradução: Marta Lança. Lisboa: Antígona, 2017. NGOMANE, Nataniel. José Craveirinha: nota biobibliográfica, Via Atlântica, São Paulo, v. 1, n. 5, p. 14-18, dez. 2002.

NOA, Francisco. Império, mito e miopia: Moçambique como invenção literária. Lisboa: Caminho, 2002.

dez. 2002

. José Craveirinha: para além da utopia, Via Atlântica, São Paulo, v. 1, n. 5, p. 68-76,

. As humanidades: entre a permanência e a finitude ou entre desassossegos e desafios, Via Atlântica, São Paulo, v. 1, n. 21, 119-130, jun. 2012.

SAID, Edward W. Orientalismo: o oriente como invenção do ocidente. Tradução: Tomás Rosa Bueno. São Paulo: Companhia das Letras, 1990.

Representações do intelectual: as Conferências Reith de 1993. Tradução: Milton Hatoum. São Paulo: Companhia das Letras, 2005.

SPIVAK, Gayatri Chakravorty. Pode o subalterno falar? Tradução: Sandra Regina Goulart Almeida, Marcos Pereira Feitosa, André Pereira Feitosa. Belo Horizonte: Editora UFMG, 2010.

\section{Minicurrículos}

Vanessa Pincerato Fernandes é graduada em Letras pela Universidade do Estado de Mato Grosso (Unemat) e mestra em Estudos de Linguagem pela Universidade Federal de Mato Grosso (UFMT).

Marinei Almeida fez doutorado (2008) e mestrado (2002) em Letras (Estudos Comparados de Literaturas de Língua Portuguesa) pela Universidade de São Paulo. É graduada em Letras (Língua Portuguesa e Inglesa e suas respectivas literaturas) pela Unemat (1996). Realiza atualmente estágio de pós-doutorado na Universidade de Lisboa/UL (2018/2019). É professora (desde 1997) na Unemat. 


\section{ANEXO}

\section{Ao meu belo pai ex-emigrante}

Pai:

As maternas palavras de signos vivem e revivem no meu sangue e pacientes esperam ainda a época de colheita enquanto soltas já são as tuas sentimentais sementes de emigrante português espezinhadas no passo de marcha das patrulhas de sovacos suando as coronhas de pesadelo.

E na minha rude e grata sinceridade não esqueço meu antigo português puro que me geraste no ventre de uma tombasana eu mais um novo moçambicano semiclaro para não ser igual a um branco qualquer e seminegro para jamais renegar um glóbulo que seja dos Zambezes do meu sangue.

E agora

para além do antigo amigo Jimmy Durante a cantar e a rir-se sem nenhuma alegria na voz roufenha subconsciência dos porquês de Buster Keaton sorumbático achando que não valia a pena fazer cara alegre e um Algarve de amendoeiras florindo na outra costa Ante os meus sócios Bucha e Estica no "écran" todo branco e para sempre um zinco tap-tap de cacimba no chão e minha Mãe agonizando na esteira em Michafutene enquanto tua voz serena profecia paternal: - "Zé: quando eu fechar os olhos não terás mais ninguém."

Oh, Pai:

Juro que em mim ficaram laivos

do luso-arábico Algezur da tua infância mas amar por amor só amo e somente posso e devo amar esta minha bela e única nação do Mundo onde minha mãe nasceu e me gerou e contigo comungou a terra, meu Pai. E onde ibéricas heranças de fados e broas se africanizaram para a eternidade nas minhas veias e teu sangue se moçambicanizou nos torrões 
da sepultura de velho emigrante numa cama de hospital colono tão pobre como desembarcaste em África meu belo Pai ex-português.

Pai:

O Zé de cabelos crespos e aloirados não sei como ou antes por tua culpa o "Trinta-Diabos" de joelhos esfolados nos mergulhos à Zamora nas balizas dos estádios descampados avançado-centro de "bicicleta" à Leónidas no capim mortífera pontaria de fisga na guerra aos gala-galas embasbacado com as proezas do Circo Pagel nódoas de cajú na camisa e nos calções de caqui campeão de corridas no "xituto" Harley-Davidson os fundilhos dos calções avermelhados nos montes do Desportivo nas gazetas à doca dos pescadores para salvar a rapariga Maureen OSullivan das mandíbulas afiadas dos jacarés do filme de Trazan Weissmuller os bolsos cheios de tingolé da praia as viagens clandestinas nas traseiras gã-galhã-galhã do carro eléctrico e as mangas verdes com sal sou eu, Pai, o "Cascabulho" para ti e Sontinho para minha Mãe todo maluco de medo das visões alucinantes de Lon Chaney com muitas caras.

Pai:

Ainda me lembro bem do teu olhar e mais humano o tenho agora na lucidez da saudade ou teus versos de improviso em loas à vida escuto e também lágrimas na demência dos silêncios em tuas pálpebras revejo nitidamente eu Buck Jones no vaivém dos teus joelhos dez anos de alma nos olhos cheios da tua figura na dimensão desmedida do meu amor por ti meu belo algarvio bem moçambicano!

E choro-te chorando-me mais agora que te conheço a ti, meu pai vinte e sete anos e três meses depois dos carros na lenta procissão do nosso funeral mas só Tu no caixão de funcionário aposentado nos limites da vida e na íris do meu olhar o teu lívido rosto ah, e nas tuas olheiras o halo cinzento do Adeus e na minha cabeça de mulatinho os últimos afagos da tua mão trémula mas decidida sinto naquele dia de visitas na enfermaria do hospital central. 
E revejo os teus longos dedos no dirlim-dirlim da guitarra ou o arco da bondade deslizando no violino da tua aguda tristeza e nas abafadas noites dos nossos índicos verões tua voz grave recitando Guerra Junqueiro ou Antero e eu ainda Ricardino, Douglas Fairbanks e Tom Mix todos cavalgando e aos tiros menos Tarzan analfabeto e de tanga na casa de madeira e zinco da estrada do Zichacha onde eu nasci.

Pai:

Afinal tu e minha mãe não morreram ainda bem mas sim os símbolos Texas Jack vencedor dos índios e Tarzan agente disfarçado em África e a Shirley Temple de sofisma nas covinhas da face e eu também é que mudámos.

E alinhavadas palavras como se fossem versos bandos de sécuas ávidas sangrando grãos de sol no tropical silo de raivas eu deixo nesta canção para ti, meu Pai, minha homenagem de caniços agitados nas manhãs de bronzes chorando gotas de uma cacimba de solidão nas próprias almas esguias hastes espetadas nas margens das úmidas ancas sinuosas dos rios.

E nestes versos te escrevo, meu Pai por enquanto escondidos teus póstumos projectos mais belos no silêncio e mais fortes na espera porque nascem e renascem no meu não cicatrizado ronga-ibérico mas afro-puro coração.

E fica a tua prematura beleza realgarvia quase revelada nesta carta elegia para ti meu resgatado primeiro ex-português número UM Craveirinha moçambicano! (CRAVEIRINHA, 1995, p. 92-95) 